\title{
Novos sujeitos da securitização global
}

Paul Amar. The security archipelago: human-security State, sexuality politics, and the end of neoliberalism. Durham/Londres, Duke University Press, 2013. 310 páginas.

\section{Osmundo Pinho}

O medo, o pânico e a reconfiguração de sujeitos sociais "perigosos" e/ou "vulneráveis" são reconhecidos combustíveis da política, e não é de hoje. Diversos trabalhos descreveram o impacto e os determinantes sociológicos das ondas ou surtos de pânico moral em diversos contextos. Stuart Hall e colaboradores (1978) discutem em estudo paradigmático dos estudos culturais britânicos a onda de terror e racismo que se seguiu à translação do mugging $^{1}$ da linguagem sensacionalista utilizada pelo jornalismo policial norte-americano para a Inglaterra. Antes deles, Stanley Cohen ajudou a definir a conotação sociológica de pânico moral na investigação sobre a ansiedade classista que a mídia ajudou a criar em torno dos Mods e Rockers britânicos, atribuindo ao termo sua definição consensual: "Sociedades parecem estar sujeitas, de vez em quando, a períodos de pânico moral. Uma condição, episódio, pessoa ou grupo emerge para tornar-se definida como um ameaça aos valores e interesse societários" (1972, p. 1). No campo da sexualidade, Lisa Duggan e Nadine Hunter (2006) demonstram como o pânico criado por feministas e insuspeitos aliados conservadores em torno da pornografia alimentou o ressentimento contra trabalhadoras sexuais e demais sujeitos "não respeitáveis". Roger Lancaster em Sex panic and the punitive State (2011), por sua vez, mostra o cortejo de injustiças e violência históricas criadas na sociedade norte-americana em torno de pânicos sexuais, como templates para instauração de modalidades punitivas de governança, baseadas na renovação do terror, do pânico e na criação de bodes expiatórios.

Contudo o que propõe Paul Amar nesse estudo, que acaba de ser premiado como "o melhor livro do ano" pela American Political Association, é algo diferente e mais radical, porque o pânico e medo, a crescente sensação de insegurança e de "crise moral", 
desenvolvida em nível global e por meios globais de articulação, não se resumem, em seu argumento, a ondas ou espasmos que elegem alvos minoritários como bodes expiatórios de ansiedade social, de natureza sexual, racial étnica ou de classe, mas que todo um novo modo de governança de alcance global está sendo agora mesmo gestado em torno da segurança e da transição dos modelos e dos discursos de base econômica - liberal ou neoliberal - a um outro baseado no que ele chama de securitization.

Como define o autor, novas modalidades de intervenção "humanitária" levadas a efeito não apenas pelo Estado, ou organismos internacionais, mas por formações paraestatais como ONGs e especialistas em desenvolvimento, visam a salvaguardar sujeitos e cenários vulnerabilizados, ou assim situados, presumidos alvos da degradação moral. A imposição e a resistência específica a essa nova doutrina é explorada por Amar por meio de diversos exemplos concretos, no Egito (Cairo) e no Brasil (Rio de Janeiro), contextos nacionais a partir de onde baseia seu argumento. $\mathrm{O}$ autor utiliza sua experiência de pesquisa nos dois contextos para sustentar que, a despeito das diferenças importantes, as duas sociedades, e Estados nacionais, compartilham algo como nações semi-industrializadas do Sul global, com uma história de autoritarismo politico, rico patrimônio cultural e articulação forte entre sexualidade/gênero e raça.

$\mathrm{O}$ argumento geral implica em reconhecer uma transição da retórica de governança, articulada no Sul global, que abandona a linguagem econômica do neoliberalismo e de suas subjetividades individualistas em nome de uma doutrina baseada na segurança das comunidades - e no retorno aos valores morais, ou da família - e das tradições religiosas e/ou culturais, como dispositivos na disputa política por legitimação e recursos. Isso implica reconhecer novas práticas repressivas articuladas à (re)invenção do Estado em suas margens (Das, 2004) e a formação de novos sujeitos da prática e da resistência política, sujeitos em larga medida justamente interpelados em função do gênero ou sexualidade: o terrorista hipermasculino, o gay global, a travesti atávica, a feminista imoral. A sexualidade seria, assim, eixo fundamental dessas novas modalidades de "resgate" humanitário, de- finindo sujeitos "para-humanos". Dessa forma "a sexualidade infunde e anima a lógica essencial da dominação securitizada” (p. 20).

Essa nova retórica política da governança interpela esses sujeitos definidos justamente como, ao mesmo tempo, vulneráveis e ameaçadores, suscetíveis de decadência ou cooptação por valores globais, ou à corrupção moral de natureza sexual ou de gênero. No Cairo, o autor testemunhou momentos decisivos da chamada Primavera Árabe e discute com acuidade o papel das violências sexuais na produção do terror e na estratégia contrarrevolucionária. A violação de ativistas por gangues armadas a serviço do Estado militarizado, batalgiyya, operou primeiro produzindo pânico e reforçando a imagem do terrorista islâmico violento e hipermasculino - porque os thugs da batalgyyia, misturados à multidão, produziram distúrbios e saques, além da violência sexual, como tentativa de desmoralizar o ativismo feminino. Dessa forma, a política da violência sexual converteu-se em uma modalidade efetiva de controle contrarrevolucionário.

Amar discute ainda, por exemplo, as políticas de reconversão da Lapa, no Rio de Janeiro, e a luta das travestis para permanecerem no local, em paralelo aos ataques ao queer globalism no Cairo, onde a polícia, em 2001 prendeu 52 homens, participantes de suposta "festa gay" em um barco que navegava no rio Nilo. Em ambos os casos, e no contexto da revolução de 2011, o autor identifica e localiza não apenas as formas de governança baseadas na purificação moral de pessoas e lugares, mas também as correspondentes formas de resistência e luta. No Cairo, o confronto em torno da Gay International, no Rio de Janeiro, a Lapa, e sua "despoluição", isto é, sua integração a novos circuitos de consumo e lazer; em uma palavra, sua salvação ou resgate.

Além da centralidade analítica que Amar atribui à luta e à resistência de sujeitos sociais heterogêneos e heterodoxos nesses dois contextos, como modalidades inovadoras de reelaboração de identidade e subjetividade - tal como entre os moradores de Madureira, no Rio de Janeiro, e suas contraditórias lutas em torno da preservação do "berço do samba", ou o protagonismo de lideranças femininas e populares do culto Zar, sob ataque da ortodoxia islâmica no centro histórico do Cairo -, em The 
security archipelago ele apresenta outra contribuição ao argumentar que essas novas constelaçôes, definidas pelo arquipélago da securitização, não são testemunhas de formas tradicionais ou decadentes que ainda sobrevivem em sociedades não modernas no Sul global. Na verdade seriam laboratórios para o futuro - a emergente face de novas modernidades e modalidades de governança -, de modo semelhante ao que argumenta, por exemplo, Achille Mbembe (2001) e Jean e John Comarroff (2006), para os quais a dimensão eventualmente distópica, autocontraditória e "híbrida" dos processos de modernização do antigo "Terceiro Mundo" são a gestação de formas emergentes de Estado e subjetivação.

Para um leitor brasileiro, o modo como o autor enfatiza as conexōes entre socialistas, nacionalistas e fundamentalistas religiosos em sua ênfase renovada nos valores morais e no "resgate" de sujeitos "para-humanos" sexualizados (vítimas de tráfico sexual ou menores expostos à "ditadura gay”) parece produzir uma ideia desconcertante. A evolução espetacular dos indicadores de criminalidade e a consequente sensação de insegurança crescem ao mesmo tempo que os discursos moralizantes de retorno à autoridade paterna e à família tradicional ganham adesão mesmo entre setores "progressistas", e mais uma vez a sexualidade e o gênero parecem ocupar o centro de toda uma constelação política, levando pânico às agendas públicas.

\section{Notas}

1 Roubo em via pública, executado mediante ameaça ou violência.

\section{BIBLIOGRAFIA}

COMAROFF, Jean \& COMAROFF, John. (2006), "Law and disorder in the postcolony: an introduction", in (eds.), Law and disorder in the postcolony, Chicago, The University of Chicago Press, pp. 1-56.

COHEN, Stanley. (1972), Folk devils and moral panics: the creation of The mods and rockers. Londres/Nova York, Routledge.
DAS, Veena. (2004), "The signature of the State: the paradox of illegibility", in Veena Das e Deborah Poole, Anthropology in the margins of the State, Santa Fé, School of American Research Press, pp. 225-252.

DUGGAN, L. \& HUNTER, N. D. (2006), Sex wars: sexual dissent and political culture. Nova York, Routledge.

HALL, Stuart et al. (1978), Policing the crisis: mugging, the State and law and order. Londres, MacMillan.

LANCASTER, Roger N. (2011), Sex panic and the punitive State. Berkeley, University of California Press.

MBEMBE, Achile. (2001), On the postcolony. Oakland, University of California Press.

OSMUNDO PINHO, doutor em ciências sociais pela Unicamp, é professor do Centro de Artes, Humanidades e Letras da Universidade Federal do Recôncavo da Bahia e, atualmente, bolsista Estágio Sênior (Capes) no African and African Diaspora Department Studies da University of Texas at Austin. E-mail: osmundopinho@gmail.com.

DOI: http//dx.doi.org/10.17666/3088188-190/2015 